\title{
SISTEMA PARA RASTREAMENTO DE ATIVOS MÓVEIS BASEADO EM COMUNICAÇÃO LPWAN: AVALIAÇÃO DO PROTOCOLO SIGFOX
}

Paulo Renato Câmera da Silva1; Herman Augusto Lepikson²; Marcus Vinícius Ivo da Silva2; Rafael Barbosa Mendes ${ }^{1,2}$; João Ricardo de Oliveira Mota ${ }^{1}$

1 Universidade Federal da Bahia; Salvador/Bahia; paulocamera1@gmail.com

2 SENAI-CIMATEC; Salvador/Bahia

Resumo: Rastreamento de ativos móveis requer conexão de objetos por rede sem fio. Dentre os protocolos de comunicação existentes, o de Low Power Wide Area Network (LPWAN) foi desenvolvido para a conexão de objetos na chamada Internet das Coisas. Este trabalho avaliou o protocolo LPWAN Sigfox para rastreamento de ativos móveis. Construiu-se um protótipo para coleta e envio de mensagens com a geolocalização do ativo através de uma rede LPWAN com o uso de dois módulos, um GPS e um Sigfox. Com o protótipo construído, esse foi testado em um cenário real para demonstrar o comportamento da rede para esse tipo de aplicação e resultados que justificam o projeto são apresentados neste trabalho. Avaliada a repetibilidade, conclui-se que a rede é satisfatória no rastreamento de longo alcance.

Palavras-Chave: LPWAN; Sigfox; GPS; Rastreamento de ativos.

\section{MOBILE ASSET TRACKING SYSTEM BASED ON LPWAN COMMUNICATION: SIGFOX PROTOCOL EVALUATION}

\begin{abstract}
Mobile asset tracking requires wireless object connection. Among the existing communication protocols, the Low Power Wide Area Network (LPWAN) was developed for the connection of objects in the so-called Internet of Things. This work evaluated the LPWAN Sigfox protocol for tracking mobile assets. A prototype was built to collect and send messages with the geolocation of the asset through an LPWAN network using two modules, one GPS and one Sigfox. With the prototype built, it was tested in a real scenario to demonstrate network behavior for this type of application and results that justify the project are presented in this paper. Evaluating repeatability, it is concluded that the network is satisfactory in long range tracking.
\end{abstract}

Keywords: LPWAN; Sigfox; GPS; Asset tracking 


\section{INTRODUÇÃO}

No Brasil, o setor de transportes cresceu, em 2018, 2,2\% em relação ao ano anterior chegando a 256,08 bilhões de reais, o que é relevante em relação ao seu PIB [1]. A demanda de rastreamento dos ativos, sejam esses de transporte de cargas ou veículos de uso geral, vem sendo atendida nas últimas décadas com uso de redes móveis que não foram desenvolvidas para esse fim, como as redes de celulares (3G, 4G ou GPRS). O advento da chamada Internet das Coisas (em inglês: Internet of Things ou loT), impulsionou o crescimento das redes de sensores sem fio (do inglês - Wireless Sensor Networks WSN) para aplicações com demandas específicas que, até o momento, eram atendidas de maneira ineficiente pelas redes existentes, como é o caso do rastreamento de ativos.

As redes WSN são redes compostas de vários nós de comunicação. Esses nós normalmente são constituídos por um sensor, um microcontrolador, um componente de comunicação e uma fonte de energia. [2] As redes WSN podem ser subdividas em redes de curto alcance ( $100 \mathrm{~m}$ ou menos de alcance) e redes de longo alcance (acima de $100 \mathrm{~m}$ podendo chegar a $50 \mathrm{~km}$ ). As redes de curto alcance são comumente utilizadas em pequenos espaços físicos ou residenciais (ex. Bluetooth, IEEE802.15.4 e/ou IEEE 802.11). Já as de longo alcance, são utilizadas em áreas urbanas e/ou em aplicações que demandem conexões em áreas mais distantes, (ex. 4G, GPRS, LTE, LPWAN).

O rastreamento de ativos móveis demanda redes de longo alcance, principalmente, nos casos em que o ativo percorre longos percursos como o rastreamento de veículos ou frotas. As redes de celulares apresentam limitações quanto a custos, consumo de energia, limites de cobertura e instabilidade. Criada para a comunicação de um pacote de no máximo pouco mais de um megabyte de dados, a tecnologia de Low Power Wide Area Network (LPWAN) atende ao rastreamento de ativos móveis, na qual, normalmente, seis a oito bytes são usados para enviar a localização e um byte para enviar a velocidade do ativo. Logo, não se faz necessário redes com grande banda de dados, mas com boa cobertura na área de interesse e pouca variação e instabilidade da rede $[3,4,5,6]$.

Diversos padrões de redes de LPWAN têm sido propostos, sendo que alguns tem se destacado no cenário mundial, como Sigfox, LoRa ${ }^{\mathrm{TM}}$, Ingenu e NB-loT. Cada uma delas introduz um modelo de negócio, adequando-as a aplicações ou mercados específicos. A Sigfox é uma rede proprietária criada na França com o objetivo de atender a demanda de dispositivos loT que necessitam de conexão sem fio com baixo custo (iniciando com pacotes de $\$ 2,00$ dólares ao ano), pouco uso de dados (as mensagens possuem um payload máximo de 12 bytes) e grande autonomia de bateria (projetos com essa tecnologia de transmissão podem chegar a 5 anos de autonomia) $[7,8,9]$.

A camada física da Sigfox utiliza a técnica de Ultra Narrow Band (UNB), para reduzir a interferência de ruídos externos mesmo com baixos níveis de sinal em relação ao ruído (em inglês: signal-to-noise ratio ou SNR). Além disso, seu protocolo trabalha com método de modulação de sinal do tipo DBPSK (Differential Binary Phase 
Shift Keying), que facilita a implantação e reduz o custo inicial dos dispositivos, uma vez que a tecnologia de alta sensibilidade, com maior custo, fica na estação base $[7,8]$.

Este trabalho buscou desenvolver um sistema de rastreamento de ativos móveis, baseado em tecnologia LPWAN, com comunicação capaz de transmitir dados de coordenadas e velocidade de um Sistema de Posicionamento Global (em inglês: Global Positioning System ou GPS) embarcado em um veículo. A verificação do comportamento da rede deveria ser realizada, principalmente, com o veículo em movimento, condição na qual as características do protocolo Sigfox deveriam garantir a qualidade de recepção e a repetibilidade do envio de mensagens para demostrar a eficácia da rede para essa aplicação. Assim, este trabalho avaliou o protocolo LPWAN Sigfox para rastreamento de ativos móveis.

\section{METODOLOGIA}

\subsection{Arquitetura do sistema}

A arquitetura do sistema usou a rede LPWAN para enviar as informações do protótipo para o aplicativo de rastreamento proposto. Para isso, foi usado o operador de rede da Sigfox, que recebe os dados enviados pelo protótipo através de um receptor proprietário e disponibiliza para um serviço de backend geral em que os dados podem ser visualizados e/ou retransmitidos para outras aplicações. O fluxo de informações de rastreamento nessa arquitetura é apresentado na Figura 1.

Figura 1. Fluxo de informações de rastreamento enviadas do protótipo para o aplicativo em uma arquitetura LPWAN com operador Sigfox. Fonte:Autor

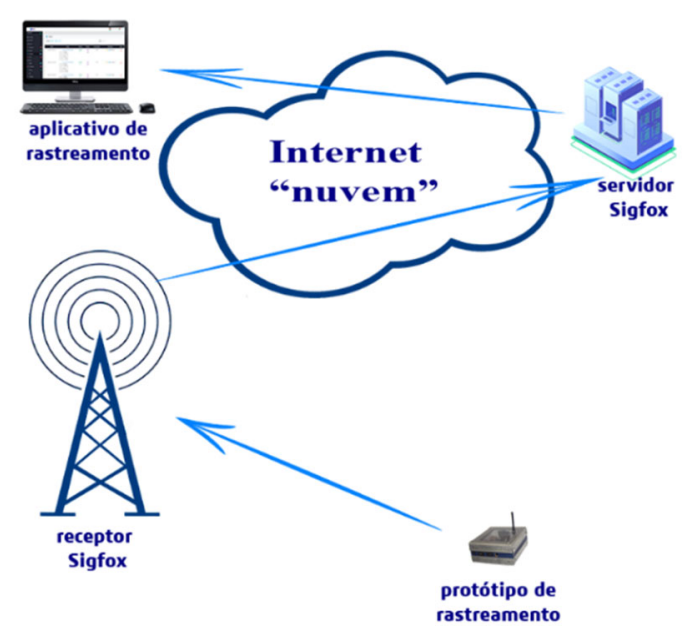

A Sigfox possui um sistema de callback para redirecionar as mensagens para outras plataformas. Esse sistema é uma função de chamada para cada mensagem 
que chega. Esta função permite redirecionar as mensagens por e-mail, ou através de HTTP para um servidor [10].

Neste trabalho, optou-se por redirecionar as mensagens para outra plataforma de dispositivos de Internet das Coisas, criada pela própria Sigfox, que possui uma interface configurável pelo usuário chamada "try.iotagency". Esse redirecionamento foi feito no backend da Sigfox por meio do mecanismo de callback HTTP. Na configuração do callback, além dos dados enviados pelo protótipo na mensagem, outros dados que são obtidos em todas as mensagens recebidas, como o signal-tonoise-ratio (SNR), o received signal strength indicator (RSSI) e o sequence number puderam ser enviados para a outra plataforma.

Optou-se por trabalhar no aplicativo "try.iotagency" por ser possível configurar a mensagem recebida de forma a torná-la de fácil compreensão para o usuário final. Essa configuração foi feita através de uma interface de programação de aplicativo (em inglês, Application Programming Interface ou API) disponibilizada na plataforma para o uso ou criação de mecanismos de publicação de dados. Além dessa facilidade e possibilidade de personalização desse aplicativo, também se tornou mais simples a exportação dos dados para uma planilha eletrônica para posterior análise, pois, nesta plataforma, todos os dados já configurados podem ser exportados em formato .CVS. $\mathrm{Na}$ Figura 2, pode ser vista a interface do aplicativo com algumas das mensagens recebidas.

Figura 2. Interface do aplicativo try.iotagency com algumas mensagens recebidas. Fonte:

Sigfox,

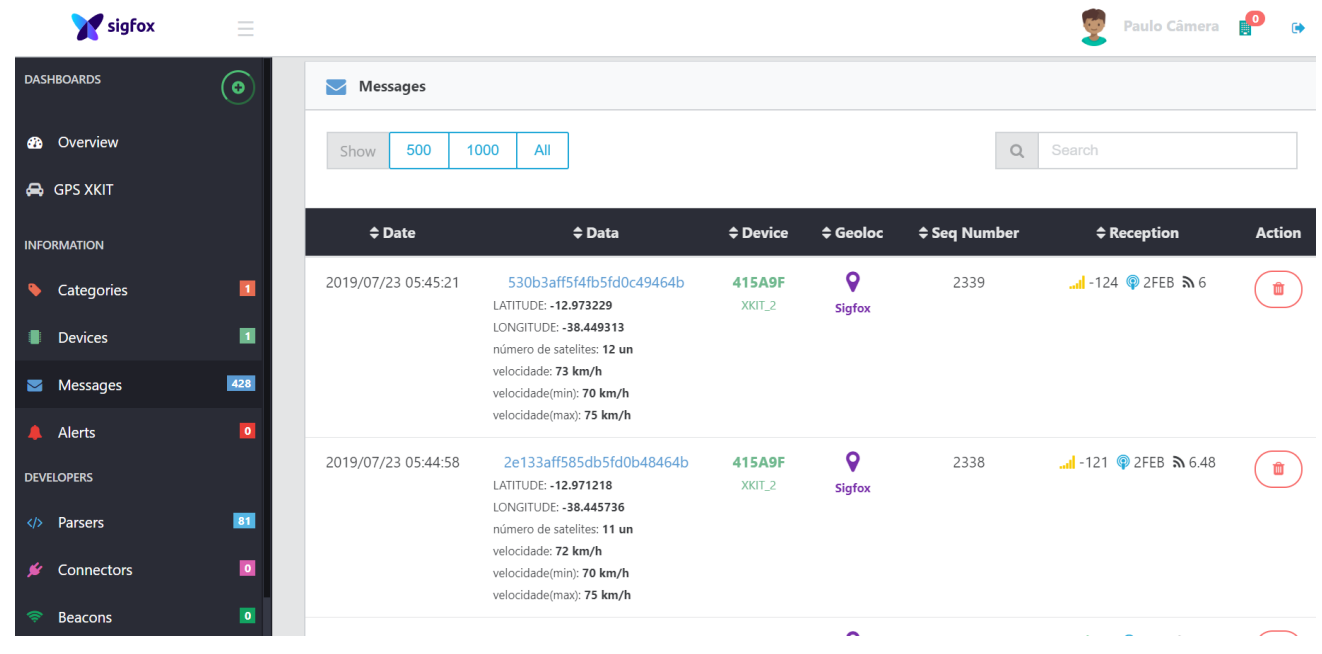

\subsection{Sistema de rastreamento de ativos móveis com rede LPWAN}

A Figura 3 mostra o diagrama de blocos do protótipo de rastreamento de ativos móveis. O protótipo utiliza uma placa de Arduino Mega 2560, que é baseado no microcontrolador Atmel $\circledast$ AVR $®$ 8-bits, de alto desempenho e baixo consumo energético. Esse microcontrolador foi escolhido também por permitir a utilização de mais de uma porta serial, o que era requerido no projeto. O Arduino Mega 2560 possui 


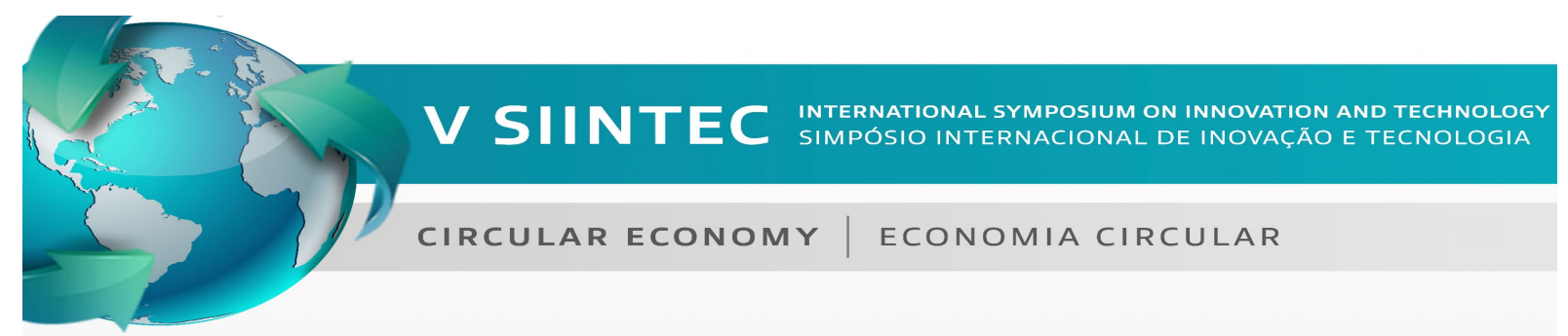

54 pinos digitais de entrada/saída, 16 entradas analógicas, 4 UARTs (Universal Asynchrounous Receiver/Transmiter), 1 porta USB, 1 conector de energia, e pode ser facilmente conectado a um computador.

Figura 3. Diagrama de blocos do protótipo de rastreamento. Fonte: Autor

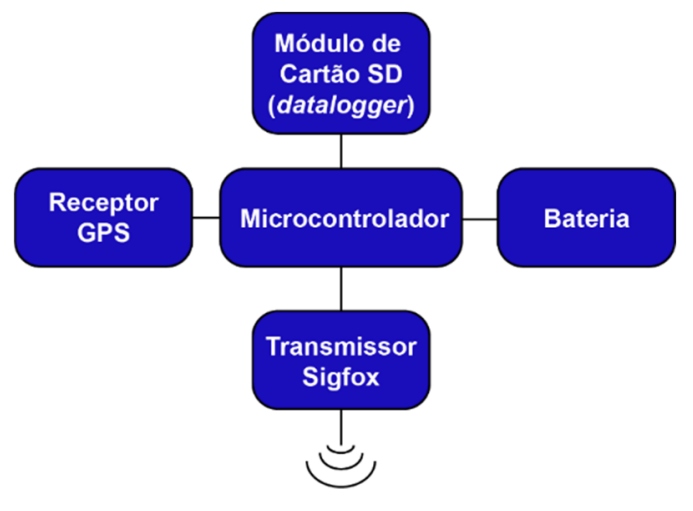

Conectado ao microcontrolador, um receptor GPS foi responsável por indicar os dados de latitude, longitude e velocidade do ativo. O receptor utilizado no protótipo foi o U-Blox-6M, cujas precisão horizontal é de $2,5 \mathrm{~m}$ e sensibilidade é de $161 \mathrm{dBm}$. Para armazenar todos os dados coletados, inclusive os dados de posicionamento das mensagens não recebidas pelas estações base da Sigfox, foi colocado um módulo de armazenamento flash (o Deek-Robot ${ }^{\mathrm{tm}}$ ID:8122) com um cartão SD de 2GB (sendo possível expandir até 4GB). Para o envio das mensagens, foi utilizado um transmissor produzido pela Wisol (o WSSFM10) operando na faixa de 902Mhz que vem embutido em uma placa de desenvolvimento produzida pela Thinxtra. Alimentando o sistema, estão dispostas três baterias de 3,7V e 2500mAh ligadas em série (Figura 3).

O firmware desenvolvido leu os dados do módulo GPS conectado à placa Arduino, guardou as informações no cartão de memória e enviou as informações pelo transmissor Sigfox. Nos testes, foram enviadas mensagens contendo o máximo de payload permitido pelo protocolo da Sigfox (12 bytes), para que fosse examinada a situação mais extrema de envio. Para realizar a tarefa de compilar os dados em uma mensagem a ser enviada, foi programado, no microcontrolador, uma rotina de compilação que reuniu os dados a serem enviados em uma variável única hexadecimal. Na Tabela 1, pode ser visto a disposição dos dados com seus respectivos tamanhos.

Tabela 1. Tamanho em bytes de cada dado enviado. Fonte: Autor

\begin{tabular}{|c|c|c|c|c|c|}
\hline Latitude & Longitude & $n^{\circ}$ de Satélites & Velocidade & Parametro1 & Parametro2 \\
\hline 4 bytes & 4 bytes & 1 byte & 1 byte & 1 byte & 1 byte \\
\hline
\end{tabular}

Os testes foram realizados no Brasil, na cidade de Salvador - BA, na Avenida Luís Viana, uma área urbana ao ar livre. O percurso percorrido foi de aproximadamente $30 \mathrm{~km}$ (Figura 4 ) e a rede no local foi considerada homogênea 
existindo estações base a uma distância mínima de 0,8 $\mathrm{km}$ e máxima de $4 \mathrm{~km}$. As mensagens foram enviadas em um intervalo de $30 \mathrm{~s}$, sendo que, por protocolo da própria Sigfox, a cada envio são realizadas três repetições em intervalo de 500 ms. Os dados foram analisados em uma planilha eletrônica para se estabelecer a porcentagem de repetibilidade da rede estipulando a eficácia dessa no rastreamento de ativos móveis.

Figura 4. Trajeto escolhido para realização do teste. Fonte: Google Maps

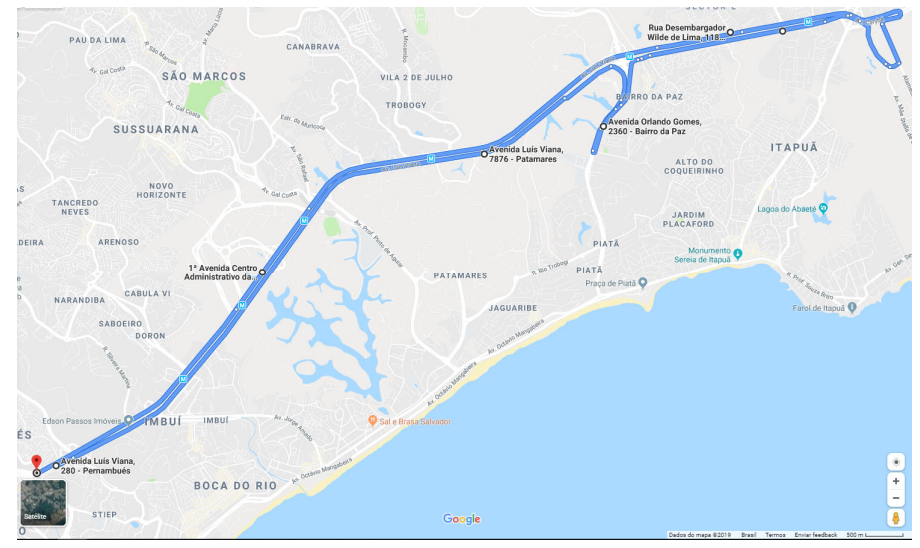

\section{RESULTADOS E DISCUSSÃO}

Com o protótipo equipado em um veículo de passeio, o teste foi efetuado pelo percurso pré-determinado. A velocidade média durante o percurso foi de $62 \mathrm{~km} / \mathrm{h}$ sendo que houve uma variação de 30 a $70 \mathrm{~km} / \mathrm{h}$. Um total de 57 mensagens foram enviadas sendo que, desse total, 53 foram recebidas por uma ou mais estações base. $\mathrm{Na}$ Figura 5, pode ser visualizado dois mapas gerados no Google Maps com as coordenadas das mensagens recebidas no teste (a) e os locais onde as mensagens foram perdidas sendo então apenas armazenadas no módulo de armazenamento flash.

Figura5. Mapas gerados com as coordenadas das 57 mensagens recebidas (a) e 5 não recebidas (b). Fonte: GoogleMaps

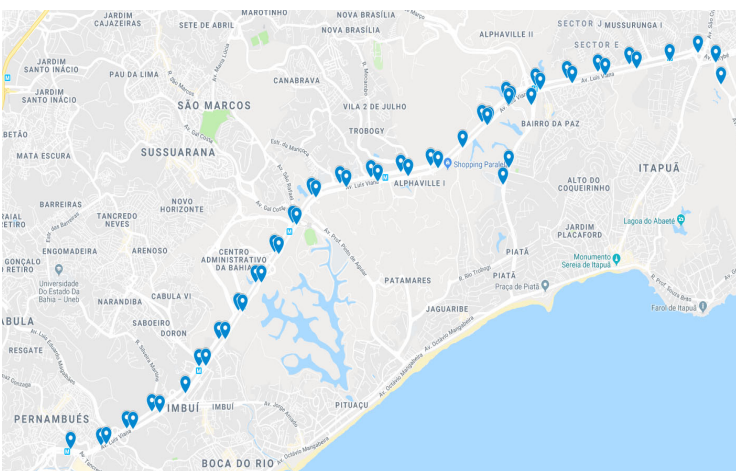

(a)

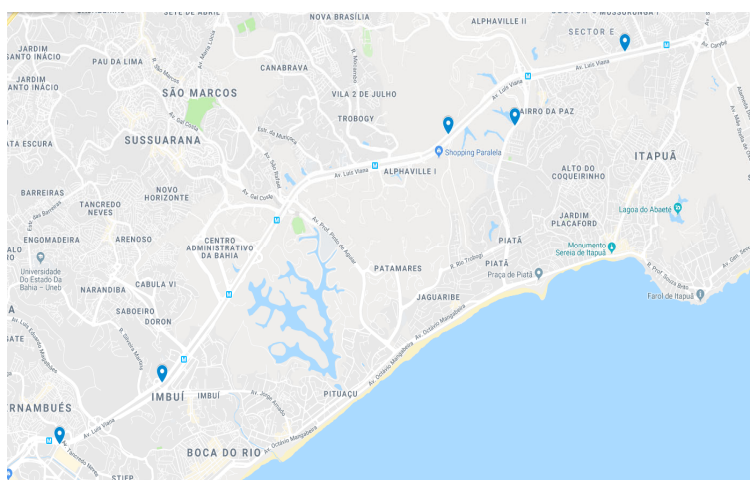

(b) 


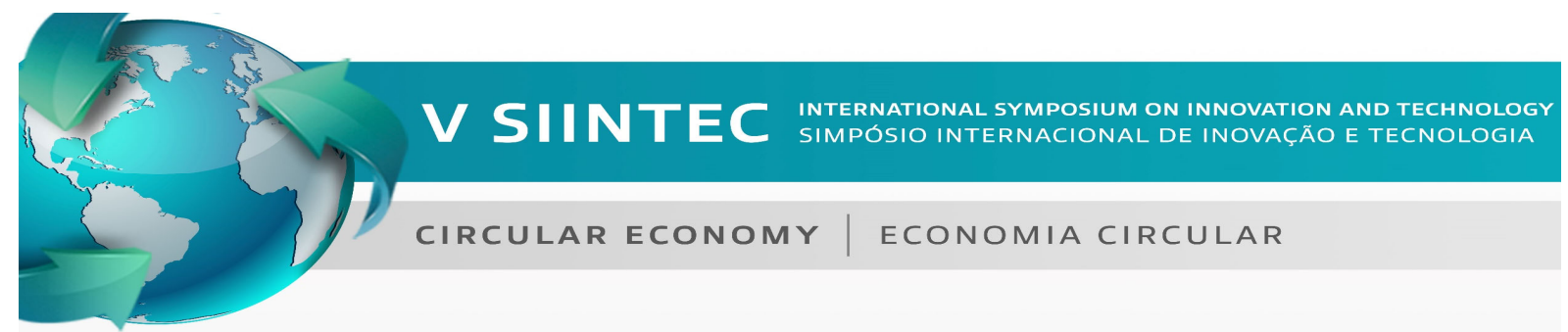

Conforme os resultados apresentados na Tabela 2, obteve-se um percentual de $91,23 \%$ de sucesso no recebimento das mensagens no teste em movimento no percurso. Comparando-o com a razão de recebimento de $98 \%$ de testes feitos em repouso na mesma área, fica evidente o impacto do movimento no sucesso de envio das mensagens para o rastreamento do ativo. Apesar disso, outros fatores como o tamanho do pacote enviado, podem também ter afetado a taxa de mensagens recebidas.

Tabela 2. Resultados da comunicação de mensagens no trajeto percorrido durante o teste de campo do protótipo de rastreamento. Fonte: Autor

\begin{tabular}{|c|c|c|}
\hline Descrição & Qtde & Razão(\%) \\
\hline Sequence number máximo & 1874 & - \\
\hline Sequence number minimo & 1817 & - \\
\hline Total de mensagens enviadas & 57 & - \\
\hline Total não recebidas no backend & 5 & 8,77 \\
\hline Total recebidas no backend & 52 & 91,23 \\
\hline
\end{tabular}

Embora o teste tenha sido feito nas condições de maior uso do pacote de dados disponíveis, o percentual de sucesso de mensagens recebidas se mostrou satisfatório para a aplicação de rastreamento de ativos, pois, estratégias podem ser criadas de maneira a diminuir a perda de informação relevante. É possível diminuir o tamanho das coordenadas de geolocalização para seis bytes, utilizando um algarismo de codificação, e, com isso, colocar a geolocalização atual e anterior na mesma mensagem. Isso faz com que só seja perdido informação no caso em que duas mensagens simultâneas sejam perdidas. Dessa maneira, no teste realizado, apesar da perda de mensagens de $8,77 \%$ a perda de informação seria nula, pois, não houve nenhum caso em que duas mensagens seguidas fossem perdidas

\section{CONCLUSÃO}

Pode-se inferir segundo os resultados que, uma vez estabelecida uma cobertura homogênea e com estações bases distribuídas em espaços estratégicos, como foi o cenário testado, a rede consegue ser eficaz na conexão de ativos, mesmo que esses estejam em movimento. Contudo, mais testes devem ser realizados de forma a isolar a variável velocidade para que se possa entender de maneira mais pragmática a interferência desta no envio das mensagens. Também é sugerido que seja realizado a manipulação de outras variáveis, à exemplo do tamanho do pacote, para que seja observado como essas variáveis interferem na taxa de recebimento das mensagens, mostrando dessa forma qual variável é mais impactante para a rede. Além disso, testes com a atual tecnologia de comunicação utilizada para o rastreamento de ativos móveis devem ser executados no mesmo trecho para que se possa comparar a repetibilidade de ambas. 
Agradecimentos

Agradecemos ao apoio financeiro da CAPES e da FAPESB e as informações cedidas pela WND Brasil.

\section{REFERÊNCIAS}

1 JC LOGÍSTICA. Setor de transporte cresce o dobro que o País em 2018. Jornal do Comercio, Porto Alegre, 15 mar. 2019. Disponivel em: $<$ https://www.jornaldocomercio.com/_conteudo/cadernos/jc_logistica/2019/03/67 4127-setor-de-transporte-cresce-o-dobro-que-o-pais-em-2018.html>.

2 GARCIA, R. F.; GIL, I. An AlternativeWearable Tracking System Based on a LowPower Wide-Area Network. Sensors, março 2017.

3. AL-FUQAHA, A. et al. Internet of things: A survey on enabling technologies. IEEE Communications Surveys \& Tutorials, 2015. 2347-2376.

4. SIGFOX. Sigfox Build. www.build.sigfox.com, 2019. Disponivel em: <https://build.sigfox.com/payload>. Acesso em: jun. 2019.

5. HSIEH, C.-L. et al. A vehicle monitoring system based on the LoRa technique. World Academy of Science, Engineering and Technology, International Journal of Mechanical, Aerospace, Industrial, Mechatronic and Manufacturing Engineering, v. 11, n. 5, p. 1093-1099, 2017.

6 MEKKI, K. et al. A comparative study of LPWAN technologies for large-scale loT deployment. ICT Express, v. 5, n. 1, p. 1-7, mar. 2019.

7 WND BRASIL. Uma visão técnica da Rede Sigfox. Embarcados, 02 ago. 2017.

8 RIBEIRO, G. G. L. et al. An Outdoor Localization System based on SigFox. 2018 IEEE 87th Vehicular Technology Conference (VTC Spring). IEEE, IEEE, 2018. $1-5$.

9 SILVA, W. R. D. et al. An Internet of Things Tracking System Approach based on LoRa Protocol. 2018 IEEE Global Communications Conference (GLOBECOM), 2018. 1-7.

10 FERNÁNDEZ-GARCIA, R.; GIL, I. An alternative wearable tracking system based on a low-power wide-area network. Sensors, v. 17, n. 3, p. 592-606, 2017. 